\title{
An Examination of Fault, Unsafe Driving Acts, and Total Harm in Car-Truck Collisions
}

The Federal Motor Carrier Safety Administration (FMCSA) has given high priority to research regarding collisions between large trucks (gross vehicle weight > 4,540 kilograms (10,000 pounds)) and other vehicles on the roadway. This research aims to improve knowledge about the high-risk behaviors of truck and passenger vehicle (car) drivers.

In 1998, large trucks accounted for 7 percent of the total vehicle miles traveled but were involved in 13 percent of all traffic fatalities $(5,374$ of 41,471). In these truck crashes, the car's occupants were much more likely than the truck driver to be killed (78 percent of the fatalities were car occupants) or injured (76 percent of the injuries were sustained by car occupants). ${ }^{(1)}$ Two-thirds of all police-reported truck crashes involved a truck and another vehicle, and 60 percent of all truck crashes involving a fatality were two-vehicle car-truck crashes. $^{(2)}$

To address this critical issue, FMCSA has set a goal to reduce truckinvolved fatal crashes by 41 percent by 2008. Meeting this goal will require improving truck safety and enhancing truck and car drivers' behavior and performance.

The Highway Safety Information System (HSIS) is a multi-State safety database that contains crash, roadway inventory, and traffic volume data for a select group of States. The participating States, California, Illinois, Maine, Michigan, Minnesota, North Carolina, Ohio, Utah, and Washington, were selected based on the quality of their data, the range of data available, and their ability to merge the data from the various files. The HSIS is used by FHWA staff, contractors, university researchers, and others to study current highway safety issues, direct research efforts, and evaluate the effectiveness of accident countermeasures.

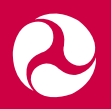

U.S. Department of Transportation Federal Highway Administration

\section{Literature Review}

A major driver behavior issue in car-truck crashes concerns fault-the relative contribution of truck vs. car drivers. In 1998, Blower analyzed more than 5,400 fatal car-truck crashes from 1994-95, examining Fatality Analysis Reporting System (FARS) records of driver-related factors, pre-crash movements, and vehicle positions. ${ }^{(2)}$ According to this analysis, the car driver's behavior was more than three times as likely to contribute to the fatal crash than was the truck driver's behavior. In addition, the car driver was solely responsible for 70 percent of the fatal crashes, compared to 16 percent for the truck driver. Blower could not replicate the analysis for nonfatal crashes, because the National Highway Traffic Safety Administration's (NHTSA) National Automotive Sampling System General Estimates System (NASS-GES) only contained contributing-factor data for cases in which a citation was written (approximately one-third of nonfatal crashes recorded in the system).

Stuster concentrated his analysis on the issue of unsafe driving acts (UDAs) in car-truck crashes, studying UDAs of car drivers. ${ }^{(3)}$ Two sets of experts-police crash investigators and truck drivers-generated a list of critical UDAs, or car-driver behaviors, that could lead to crashes. Stuster then reviewed more than 1,000 crash reports from 7 States; this produced primary collision factors that very closely matched the list from the experts as well as driver-related factors in FARS. Twenty-five experts then ranked, from highest to lowest, the combined list of 26 UDAs on both estimated relative frequency and relative severity, as shown in table 1 . 
Table 1. Experts' ranking of criticality of UDAs based on danger and frequency (from Stuster ${ }^{(3)}$ )

\section{RANK UNSAFE DRIVING ACT}

1 Driving inattentively (e.g., reading, talking on the phone, fatigue-induced)

$2 \quad$ Merging improperly into traffic, causing a truck to maneuver or brake quickly

3 Failure to stop for a stop sign or light (also, early or late through a signal)

4 Failure to slow down in a construction zone

5 Unsafe speed (e.g., approaching too fast from the rear/misjudging truck's speed)

$6 \quad$ Following too closely

7 Failure to slow down in response to environmental conditions (e.g., fog, rain, smoke, bright sun)

8 Changing lanes abruptly in front of a truck

$9 \quad$ Driving in the "no zones" (left rear quarter, right front quarter, and directly behind)

10 Unsafe turning, primarily turning with insufficient headway

10 Unsafe passing, primarily passing with insufficient headway

10 Pulling into traffic from roadside in front of truck without accelerating sufficiently

13 Driving while impaired by alcohol or other drug

14 Changing lanes in front of a truck, then braking (for traffic, obstacle, toll gate, etc.)

15 Unsafe crossing, primarily crossing traffic with insufficient headway

16 Driving left of center into opposing traffic

17 Failure to permit a truck to merge

18 Failure to discern that the trailer of a maneuvering truck is blocking the roadway

19 Nearly striking the front or rear of a truck or trailer while changing lanes

\begin{tabular}{ll}
\hline 20 & Maneuvering to the right of a truck that is making a right turn (the "right-turn squeeze") \\
\hline 21 & Operating at dawn or dusk without headlights \\
\hline 22 & Crossing a lane line near the side of a truck or trailer while passing \\
\hline 23 & Driving between large trucks \\
\hline 25 & Nearly striking the rear of a truck or trailer that is stopped or moving slowing in traffic \\
\hline 26 & Nearly striking an unattended or parked truck at roadside \\
\hline
\end{tabular}

In other UDA-related research, Kostyniuk, Streff, and Zarajsek used 1995-98 FARS data to identify car-truck UDAs and compare UDAs in car-truck crashes with those in car-car crashes. ${ }^{(4)}$ The study concluded that most driving behaviors are equally likely to be recorded for fatal car-car crashes as for fatal car-truck crashes. Only four factors (out of 94) were more likely to occur in fatal car-truck crashes-following improperly, driving while drowsy or fatigued, changing lanes improperly, and driving with vision obscured by rain, snow, fog, or dust. However, only about 5 percent of all cartruck crashes in the database included these four factors.

In summary, the past literature indicates that fault is more likely to be attributed to car drivers than to truck drivers in fatal crashes, but there is a need for information on assigned fault in nonfatal/total crashes. In addition, although researchers used a sample of 1,000 crashes to verify previously identified UDAs, final UDA rankings were based on expert opinion. There is a need to further verify these findings with crash data, where possible. Finally, none of the previous studies 
has associated critical crash types or maneuvers with specific roadway characteristics. Such an analysis could help define new roadway-based countermeasures and inform efforts to improve driver behaviors and vehicle performance. This current study attempts to meet these needs.

\section{Methodology}

\section{Databases Used}

Because the goal of this fault analysis was to examine driver contributions for all crashes rather than just fatal ones, researchers used the North Carolina database in the Highway Safety Information System (HSIS). Researchers also used these files to link crash data with roadway inventory data to analyze critical crash type/roadway characteristics.

To validate the UDA listing and ranking from the earlier study, researchers used the 1999 NASS-GES data, which contained 9,136 raw car-truck crashes. Using the GES weights, this total sample is estimated to represent 268,914 car-truck crashes.

\section{Analysis Methods}

\section{Fault Analysis}

In the 16,264 car-truck crashes in the 1994-97 North Carolina HSIS files, the investigating officer assigned one or more contributing factors (from a list of 26 factors) to one or both drivers in more than 97 percent of the cases. Contributing factors included such things as driving under the influence and improper equipment. In this analysis, fault was assigned if any factor was coded for a given driver. A contingency table analysis examined the percentage of total cases in which:

1) Only the truck driver was at fault.

2) Only the car driver was at fault.

3) Both truck and car drivers were at fault.

4) Neither driver was at fault.

Differences between the at-fault percentages found here and in the earlier fatal crash studies were explored.

\section{Crash-Based Validation of UDAs}

Using Stuster's listing of 26 UDAs, researchers examined the GES coding definitions for the complete set of NASS-GES crash, vehicle, and driver variables to try to match each UDA with a definable subset of crash data. For example, for "abandoning vehicle in travel lane," the accident-type variable was used to identify crashes in which the truck was moving forward, and "event" data were used to find cases in which a car in the travel lane was without a driver. With other UDAs, the choice of subset was not well defined (e.g., "inattentive driving").

Only 17 of the 26 UDAs could be matched with crash subsets. This does not imply that the other nine are not important, only that there was no well-defined crash subset based on available GES variables.

For UDAs for which a valid subset of crashes could be identified, researchers extracted information about crash frequency and severity. These subsets then were ranked based on frequency of car-truck crashes and the percentage of serious or fatal crashes in the subset. The two rankings were combined and compared to Stuster's ranking.

\section{Critical Combinations of Crash and Roadway Location Types}

The goal of this analysis was to use the 1994-97 North Carolina HSIS car-truck crash data to identify critical combinations of crash and roadway location factors (combinations that produce the greatest amount of harm) that would help highway officials prioritize areas for applying existing treatments or developing new countermeasures.

Car-truck crashes are more severe than other types of crashes, and some potentially important subsets may be characterized either by low frequency, high severity (e.g., head-on crashes) or by high frequency, low severity (e.g., rear-end crashes). Therefore, to identify potential treatment targets, it is important to combine crash frequency and severity in the analysis, and to use both simultaneously to avoid biasing the outcome by choosing one or the other first. To do this, researchers defined a measure of comprehensive cost associated with the driverinjury severity for each vehicle in a crash. The dollar values for the injuries sustained by the truck and car drivers in each crash were added to get the total crash harm cost. Costs were based on guidance from the Office of the Secretary of Transportation combined with information from a recent study of crash cost conducted by Blincoe, et al. for NHTSA: ${ }^{(5)}$ 
- Fatal injury

- Nonfatal injury

$\$ 3$ million

$\$ 63,000$

- No injury (cost per vehicle) $\$ 2,250$

(Thus, $\$ 4,500$ for two vehicles)

This calculated harm cost then was attached to each of the 16,264 car-truck crash records. To identify critical combinations, the records were categorized into a 462-cell matrix based on the descriptors of 11 facility types, 7 crash types, and 6 location types (see table 4 on p. 7). A regression model was used to smooth the estimate of harm cost within each of the cells where adequate data existed. Researchers then calculated the total harm cost for each combination by multiplying this average crash harm cost for a cell by the frequency of crashes in that cell. The cells producing the highest total harm cost defined the most critical combinations of facility type, crash type, and location type.

\section{Results}

Fault Analysis

Table 2 provides the distributions of fault by crash type for the 16,264 North Carolina car-truck crashes. The results differ significantly at times from the earlier cited findings in which the car driver alone was at fault in 70 percent of all fatal car-truck crashes.

As shown in the bottom ("total") row of the table, the truck driver is more likely to be assigned fault overall-48.0 percent vs. 40.2 percent for the car driver. As might be expected, the highest category of truck fault is the less-severe "backing" category (i.e., 82 percent vs. 10 percent for car drivers). The truck driver is also more likely to be at fault in both categories of rear-end crashes, right-turn crashes involving vehicles on the same road, left-turn crashes

\begin{tabular}{|c|c|c|c|c|c|}
\hline CRASH TYPE & $\begin{array}{c}\text { TRUCK } \\
\text { AT FAULT }\end{array}$ & $\begin{array}{c}\text { CAR } \\
\text { AT FAULT }\end{array}$ & $\begin{array}{c}\text { BOTH } \\
\text { AT FAULT }\end{array}$ & $\begin{array}{l}\text { NEITHER } \\
\text { AT FAULT }\end{array}$ & TOTAL \\
\hline Rear-end slow & $\begin{array}{r}2,127 \\
(50.7 \%)\end{array}$ & $\begin{array}{r}1,722 \\
(41.0 \%)\end{array}$ & $\begin{array}{r}258 \\
(6.1 \%)\end{array}$ & $\begin{array}{r}92 \\
(2.2 \%)\end{array}$ & 4,199 \\
\hline Rear-end turn & $\begin{array}{r}203 \\
(51.5 \%)\end{array}$ & $\begin{array}{r}142 \\
(36.0 \%)\end{array}$ & $\begin{array}{r}42 \\
(10.7 \%)\end{array}$ & $\begin{array}{r}7 \\
(1.8 \%)\end{array}$ & 394 \\
\hline $\begin{array}{l}\text { Left turn-both } \\
\text { same roadway }\end{array}$ & $\begin{array}{r}646 \\
(45.4 \%)\end{array}$ & $\begin{array}{r}549 \\
(38.6 \%)\end{array}$ & $\begin{array}{r}200 \\
(14.1 \%)\end{array}$ & $\begin{array}{r}28 \\
(2.0 \%)\end{array}$ & 1,423 \\
\hline $\begin{array}{l}\text { Left turn—crossing } \\
\text { traffic }\end{array}$ & $\begin{array}{r}413 \\
(42.9 \%)\end{array}$ & $\begin{array}{r}466 \\
(48.4 \%)\end{array}$ & $\begin{array}{r}67 \\
(7.0 \%)\end{array}$ & $\begin{array}{r}16 \\
(1.7 \%)\end{array}$ & 962 \\
\hline $\begin{array}{l}\text { Right turn—both } \\
\text { same roadway }\end{array}$ & $\begin{array}{r}330 \\
(43.1 \%) \\
\end{array}$ & $\begin{array}{r}272 \\
(35.5 \%) \\
\end{array}$ & $\begin{array}{r}142 \\
(18.5 \%) \\
\end{array}$ & $\begin{array}{r}22 \\
(2.9 \%) \\
\end{array}$ & 766 \\
\hline $\begin{array}{l}\text { Right turn-crossing } \\
\text { traffic }\end{array}$ & $\begin{array}{r}135 \\
(36.2 \%) \\
\end{array}$ & $\begin{array}{r}203 \\
(54.4 \%) \\
\end{array}$ & $\begin{array}{r}27 \\
(7.2 \%)\end{array}$ & $\begin{array}{r}8 \\
(2.1 \%)\end{array}$ & 373 \\
\hline Head-on & $\begin{array}{r}50 \\
(22.5 \%) \\
\end{array}$ & $\begin{array}{r}158 \\
(71.2 \%) \\
\end{array}$ & $\begin{array}{r}9 \\
(4.1 \%) \\
\end{array}$ & $\begin{array}{r}5 \\
(2.3 \%) \\
\end{array}$ & 222 \\
\hline Sideswipe & $\begin{array}{r}1,813 \\
(51.1 \%) \\
\end{array}$ & $\begin{array}{r}1,246 \\
(35.1 \%) \\
\end{array}$ & $\begin{array}{r}380 \\
(10.7 \%) \\
\end{array}$ & $\begin{array}{r}109 \\
(3.1 \%)\end{array}$ & 3,548 \\
\hline Angle & $\begin{array}{r}1,371 \\
(39.3 \%) \\
\end{array}$ & $\begin{array}{r}1,690 \\
(48.5 \%) \\
\end{array}$ & $\begin{array}{r}276 \\
(7.9 \%)\end{array}$ & $\begin{array}{r}150 \\
(4.3 \%)\end{array}$ & 3,487 \\
\hline Backing & $\begin{array}{r}725 \\
(81.5 \%) \\
\end{array}$ & $\begin{array}{r}86 \\
(9.7 \%) \\
\end{array}$ & $\begin{array}{r}52 \\
(5.8 \%)\end{array}$ & $\begin{array}{r}27 \\
(3.0 \%)\end{array}$ & 890 \\
\hline Total & $\begin{array}{r}7,813 \\
(48.0 \%)\end{array}$ & $\begin{array}{r}6,534 \\
(40.2 \%)\end{array}$ & $\begin{array}{r}1,453 \\
(8.9 \%)\end{array}$ & $\begin{array}{r}464 \\
(2.9 \%)\end{array}$ & 16,264 \\
\hline
\end{tabular}


involving an opposing vehicle on the same road, and sideswipe crashes. These findings are in contrast to the fatal crash findings in which car drivers were assigned a contributing factor two to four times more often than were truck drivers in all crash types. $^{(2)}$ Car drivers are still more likely to be assigned a fault factor in head-on crashes, angle crashes, right-turn crashes involving crossing traffic, and left-turn crashes involving vehicles on the crossing road. Although a bias in crash reporting could be responsible for part of this overrepresentation of car driver fault (because the car driver is more likely to be killed in these crashes), car drivers are more likely to be at fault than truck drivers even in the nonfatal cases examined here.

\section{Crash-Based Validation of UDAs}

As noted above, crash subsets were only identified for 17 of the 26 UDAs in Stuster's report. ${ }^{(3)}$ Eight of these fell in the top half of the experts' ranking, as shown in table 3.

Table 3. Crash totals, percentages, and rankings for UDAs where GES data were sufficient

\begin{tabular}{|c|c|c|c|c|c|}
\hline \multirow[b]{2}{*}{ UNSAFE DRIVING ACTS } & \multirow{2}{*}{$\begin{array}{c}\text { PERCENT } \\
\text { OF TOTAL } \\
\text { CAR-TRUCK } \\
\text { CRASHES }\end{array}$} & \multirow{2}{*}{$\begin{array}{l}\text { PERCENT } \\
\text { SERIOUS } \\
\text { OR FATAL } \\
\text { CRASHES }\end{array}$} & \multirow[b]{2}{*}{$\begin{array}{l}\text { COMBINED } \\
\text { GES RANK }\end{array}$} & \multicolumn{2}{|c|}{$\begin{array}{l}\text { EXPERT RANKING } \\
\text { (STUSTER, 1999) }\end{array}$} \\
\hline & & & & Original & Adjusted* \\
\hline \multicolumn{6}{|l|}{ Judgment Problems } \\
\hline Failure to stop for a stop sign or signal & 0.9 & 20.0 & Tie 4 & 3 & 2 \\
\hline Driving while impaired by alcohol or other drug & 1.7 & 19.2 & Tie 4 & 14 & 9 \\
\hline $\begin{array}{l}\text { Maneuvering to the right of a truck that is } \\
\text { making a right turn (the "right-turn squeeze") }\end{array}$ & 3.0 & 3.1 & 12 & 20 & 13 \\
\hline $\begin{array}{l}\text { Nearly striking the rear of a truck or trailer } \\
\text { that is stopped or moving slowly in traffic }\end{array}$ & 5.4 & 8.9 & Tie 4 & 24 & 15 \\
\hline $\begin{array}{l}\text { Nearly striking an unattended or parked } \\
\text { truck at roadside }\end{array}$ & 0.0 & 9.9 & Tie 14 & 25 & 16 \\
\hline \multicolumn{6}{|l|}{ Speed-Related Problems } \\
\hline Failure to slow down in a construction zone & 0.0 & 0.0 & 17 & 4 & 3 \\
\hline Unsafe speed & 5.2 & 14.5 & Tie 1 & 5 & 4 \\
\hline $\begin{array}{l}\text { Failure to slow down in response to } \\
\text { environmental conditions }\end{array}$ & 2.3 & 8.3 & 9 & 7 & 5 \\
\hline \multicolumn{6}{|l|}{ Right-of-Way or Headway-Related Problems } \\
\hline $\begin{array}{l}\text { Unsafe turning, primarily turning with } \\
\text { insufficient headway }\end{array}$ & 4.3 & 10.5 & 7 & 10 & Tie 7 \\
\hline $\begin{array}{l}\text { Unsafe passing, primarily passing with } \\
\text { insufficient headway }\end{array}$ & 0.9 & 13.5 & 8 & 10 & Tie 7 \\
\hline Driving left of center or into opposing traffic & 4.8 & 17.0 & Tie 1 & 16 & 11 \\
\hline $\begin{array}{l}\text { Crossing a lane line near the side of a } \\
\text { truck or trailer while passing }\end{array}$ & 0.5 & 12.1 & Tie 10 & 22 & 14 \\
\hline $\begin{array}{l}\text { Unsafe crossing, primarily crossing traffic } \\
\text { with insufficient headway }\end{array}$ & 1.8 & 20.0 & 3 & 15 & 10 \\
\hline \multicolumn{6}{|l|}{ Lane Change or Lane Position Problems } \\
\hline $\begin{array}{l}\text { Merging improperly into traffic, causing a } \\
\text { truck to maneuver or brake quickly }\end{array}$ & 0.1 & 9.0 & 13 & 2 & 1 \\
\hline Changing lanes abruptly in front of a truck & 4.4 & 2.4 & Tie 10 & 8 & 6 \\
\hline $\begin{array}{l}\text { Nearly striking the front or rear of a truck } \\
\text { or trailer while changing lanes }\end{array}$ & 0.4 & 5.4 & 16 & 19 & 12 \\
\hline \multicolumn{6}{|l|}{ Miscellaneous } \\
\hline $\begin{array}{l}\text { Abandoning vehicle in travel lane/ } \\
\text { impeding traffic }\end{array}$ & 0.6 & 3.3 & Tie 14 & 26 & 17 \\
\hline
\end{tabular}


Of initial interest is the relatively low percentage of total car-truck crashes represented by any single UDA. If the weighted GES data are accurate, the seven highest frequency UDAs each represent between 2-6 percent of total car-truck crashes. Of the eight matched UDAs ranked by the experts in the top half of their rankings, four were present in 2.2-5.2 percent of total car-truck crashes, but each of the remaining four were present in fewer than 1 percent of car-truck crashes.

Again note that some of the UDAs from past research that would be expected to have the largest crash frequencies (e.g., "driving inattentively") were not analyzed in this study. In addition, some of the estimates provided may be somewhat conservative, given the difficulty in specifically defining the UDAs with GES variables. However, at least some of the higher ranked UDAs from past research are included here, and even some of those are present in a small percentage of the total car-truck crashes.

Interestingly, most of these UDAs have high severity levels. When researchers examined the sample of all 1999 GES car-truck crashes, 5.5 percent involved serious or fatal injuries. Twelve of the 17 UDAs in this table were of high severity. The experts who provided the ranked UDAs in the past study might have been more influenced by severity than by crash frequency.

Finally, to examine a relative ranking of these UDAs, a rank from 1 (highest frequency) to 17 (lowest frequency) was assigned, along with a similar severity-based ranking based on the percent of serious/fatal crashes. As shown in the "combined GES rank" column, these two ranks are combined to provide an overall GES ranking. For comparison, the experts' rankings are shown in the last two columns, with the final column showing the experts' relative rankings for these 17 UDAs. Although there are some similarities between the combined GES rankings and the expert relative rankings, there are some obvious differences. For example, while "driving left of center or into opposing traffic" is one of the two top-ranked UDAs based on the GES data, the experts would rank it eleventh. The experts would rank "merging improperly into traffic, causing a truck to maneuver or brake quickly" first, but this same UDA was ranked thirteenth based on the GES data. "Failure to slow down in a construction zone" would be ranked third by the experts, but seventeenth (last) by the GES data.

\section{Critical Combinations of Crash and Roadway Location Types}

Of the 462 possible combinations of facility type, location type, and crash type, 343 had sufficient data for analysis. Table 4 presents the combinations, crash frequencies, and total harm cost for the top 20 combinations. Those with total harm cost above $\$ 18.57$ million (i.e., the top 15) were at least 2 standard deviations above the average total harm cost of $\$ 3.30$ million per combination. 
Table 4. Combinations of facility type, crash type, and location type showing highest total harm cost (North Carolina car-truck crashes, 1994-97)

\begin{tabular}{|lllcc}
\multicolumn{1}{c}{ FACILITY TYPE } & $\begin{array}{l}\text { CRASH } \\
\text { TYPE } \\
\text { Other rural major roads undivided }\end{array}$ & $\begin{array}{l}\text { LOCATION } \\
\text { TYPE } \\
\text { Angle }\end{array}$ & $\begin{array}{c}\text { CRASH } \\
\text { FREQUENCY } \\
\text { intersections }\end{array}$ & $\begin{array}{c}\text { TOTAL HARM } \\
\text { COST (\$) }\end{array}$ \\
\hline Other rural major roads undivided & Head-on & Segment & 92 & $70,998,000$ \\
\hline Urban interstate/freeways/expressways & Angle & Segment & 523 & $43,722,000$ \\
\hline Other rural major roads undivided & Angle & Segment & 291 & $35,162,000$ \\
\hline Other rural major roads undivided & Left-turn & $\begin{array}{l}\text { Stop/yield } \\
\text { intersections }\end{array}$ & 280 & $34,926,000$ \\
\hline Rural principal arterial undivided & Head-on & Segment & 36 & $27,785,000$ \\
\hline Other rural major roads undivided & Rear-end & Segment & 438 & $27,526,000$ \\
\hline Rural interstate/freeways & Angle & Segment & 217 & $25,770,000$ \\
\hline Rural principal arterial undivided & Rear-end & Segment & 181 & $25,708,000$ \\
\hline Rural interstate/freeways & Rear-end & Segment & 390 & $23,699,000$ \\
\hline Other rural major roads undivided & Left-turn & Driveway & 259 & $23,067,000$ \\
\hline Rural interstate/freeways & Sideswipe & Segment & 592 & $22,993,000$ \\
\hline Other rural major roads undivided & Angle & Driveway & 141 & $19,872,000$ \\
\hline Rural principal arterial undivided & Angle & Segment & 99 & $19,802,000$ \\
\hline Other rural major roads undivided & Rear-end & Driveway & 228 & $18,913,000$ \\
\hline Urban interstate/freeways/expressways & Rear-end & Segment & 722 & $18,543,000$ \\
\hline Other rural major roads undivided & Sideswipe & Segment & 382 & $15,631,000$ \\
\hline Rural principal arterial undivided & Angle & Stop/yield & 60 & $15,348,000$ \\
\hline intersections & & \\
\hline Urban collectors/minor arterials & Angle & Stop/yield & 112 & $15,099,000$ \\
\hline Rural principal arterial undivided & Sideswipe & Segment & 122 & $14,653,000$ \\
\hline & & & & \\
\hline
\end{tabular}

The highest total harm cost for car-truck crashes, and thus perhaps the most important target for intervention, were angle crashes at stop/yield intersections on "other rural major roads, undivided." This road class includes minor arterials and major collectors. Sorting the data indicated that this facility class is the most prevalent in both the top 20 and in those above 2 standard deviations. "Rural principal arterial, undivided" is the second most prevalent facility type, and rural and urban interstates are present, but in lower numbers. The predominant crash type is "angle collisions." (For interstates and other divided roads, this category often includes lane change or merging collisions at some angle greater than what would be considered a sideswipe crash.) The total harm methodology successfully combined frequency and severity, as indicated by the inclusion of some head-on and rear-end categories in this top 20.

\section{Gonclusions and Reeommendations}

The findings of the fault and UDA analyses differ somewhat from earlier findings. Although part of this difference could be because data from only one State (North Carolina) were used in two of these analyses (because no national database provided the necessary variables), it is more likely that the primary differences are a result of the different databases used (fatal crashes vs. total crashes and expert opinion vs. crash analyses).

1. Unlike earlier fatality-based analyses in which the car driver was found to be primarily at fault, (indicating a need to target car drivers for interventions), these findings clearly indicate a need to target truck driver actions, as well (e.g., rearend crashes). 
2. It is difficult to identify individual UDAs that account for a significant proportion of car-truck crashes, and the UDAs identified and ranked by experts do not agree very well with crash-based analysis, at least for the subset of UDAs where NASS-GES data could be used. This suggests that if such UDA-based findings are to be used to develop new treatments or target existing treatments, improved methods to identify UDAs for both car and truck drivers are needed.

3. It is possible to identify critical combinations of roadway type, roadway location, and crash type that produce the most total harm. This allows researchers to combine crash frequency and severity in the same analysis, and identify important roadway types, locations, and crash types. This type of analysis could be expanded to include additional factors such as pre-crash maneuvers, driver characteristics, and others to target existing treatments better or identify specific areas where new treatments need to be developed.

The results of this effort indicate high-impact areas for future countermeasure research related to car-truck collisions. Driver, vehicle, or roadway treatment programs for truck drivers should address backing, rear-end, right- and leftturn, and sideswipe collisions, because truck drivers are more likely to be at fault in such crashes. Similar treatment programs for car drivers should focus on head-on and angle collisions. More research is needed into the driver- and roadway-related causes for these critical crash types.

Unfortunately, there is no strong consensus between the current crashbased findings and the earlier expert rankings of the most important UDAs, although both sources agree that crashes involving vehicles that do not stop at a sign/signal and crashes involving unsafe speed are important targets. More crash-based validation of expert opinions is needed; this will require defining additional critical UDAs (e.g., "inattention") in a crash database. Finally, based on the harm analysis, there is a need to explore driver, vehicle, or roadway programs aimed at rural undivided roads and, in particular, to intersection and segment angle and merging crashes and head-on crashes. Interstate/freeway treatments aimed at reducing car-truck crashes should concentrate on elements that affect lane-change/merging crashes and rear-end crashes.

\section{REFERENGES}

1. Traffic Safety Facts 1998 Large Trucks, Publication

No. DOT HS 808 952,

U.S. Department of

Transportation, National

Highway Traffic Safety

Administration, Washington,

DC, 1999.

2. Blower, D. The Relative

Contribution of Truck Drivers and

Passenger Vehicle Drivers to Truck-

Passenger Vehicle Traffic Crashes,

Publication No. UMTRI-98-25,

University of Michigan

Transportation Research Institute,

Ann Arbor, MI, June 1998.

3. Stuster, J. The Unsafe Driving Acts of Motorists in the Vicinity of

Large Trucks, U.S. Department of

Transportation, Federal Highway

Administration, Washington, DC,

February 1999.

4. Kostyniuk, L.P., F.M. Streff, and

J. Zarajsek. Identifying Unsafe Driver

Actions that Lead to Fatal Car-Truck

Crashes, AAA Foundation for Traffic

Safety, Washington, DC, April 2002.

5. Blincoe, L., A. Seay, E. Zaloshnja,

T. Miller, E. Romano, S. Luchter, and

R. Spicer. The Economic Impact of Motor

Vehicle Crashes 2000, Publication No.

DOT HS 809 446, U.S. Department of

Transportation, National Highway Traffic

Safety Administration, Washington, DC,

May 2002.

\section{FOR MORE INFORMATION}

This research was conducted under the HSIS project by F.M. Council and D.L. Harkey of the University of North Carolina (UNC) Highway Safety Research Center, D.T. Nabors of BMI, A.J. Khattak of the UNC Department of City and Regional Planning, and Y.M. Mohamedshah of LENDIS. The full report, Examination of 'Fault,' 'Unsafe Driving Acts,' and 'Total Harm' in Car-Truck Collisions, can be found in Transportation Research Record 1830 (TRB, 2003).

For more information about HSIS, contact Carol Tan, HSIS Program Manager, HRDS, 202-493-3315, carol.tan@fhwa.dot.gov.

\section{Visit us on the Woh at wwothrogor}

